\title{
NEOLIBERALISMO, DESIGUALDADE E DEMOCRACIA: DISCUSSÃO FUNDAMENTADA NOS CONSELHOS ECONÔMICOS E SOCIAIS
}

\author{
NEOLIBERALISM, INEQUALITY AND DEMOCRACY: A DISCUSSION BASED ON ECONOMIC AND SOCIAL COUNCILS \\ NEOLIBERALISMO, DESIGUALDAD Y DEMOCRACIA: UNA DISCUSIÓN BASADA EN LA EXPERIENCIA DE LOS CONSEJOS \\ ECONÓMICOS Y SOCIALES
}

\section{RESUMO}

Este artigo procura alinhavar o contexto econômico e político da segunda metade do século XX à discussão sobre democracia e participação social, a fim de analisar criticamente arranjos institucionais, como os conselhos econômicos e sociais, que é uma alternativa para a ampliação do diálogo social. As políticas neoliberais implementadas no final do séc. XX e início do séc. XXI têm levado a democracia representativa à crise de legitimidade, que é um problema, porque tende a distanciar a sociedade de seus governantes e, ao mesmo tempo, viabilizar a implementação de políticas favoráveis à elite influente. Uma das alternativas frequentemente apontadas para resolver ou amenizar essa questão é a maior participação social e, dentro disso, a criação de um diálogo social institucionalizado. Com base na experiência dos conselhos econômicos e sociais, este artigo questiona essa saída para superar a crise da democracia representativa. Argumenta-se que sua raiz está no neoliberalismo porque, ao reduzir a regulação estatal e aprofundar a desigualdade social, libera o poder econômico para capturar de diversas maneiras os representantes políticos. Isso pode contaminar os espaços democráticos representativos e os diálogos alternativos, além de ampliar a possibilidade de torná-los instâncias meramente legitimadoras de seus interesses, como parece ser 0 caso dos conselhos econômicos e sociais.

PALAVRAS-CHAVE: Neoliberalismo, democracia, desigualdade, participação social, conselhos econômicos e sociais.

André Pereira Carneiro

anpeca@terra.com.br

Thiago Fontelas Rosado Gambi

thiago.gambi@uol.com.br

Universidade Federal de Alfenas, Alfenas, MG, Brasil

Submetido 22.05.2017. Aprovado 08.04.2018

Avaliado pelo processo de double blind review.

DOI: http://dx.doi.org/10.12660/cgpc.v23n74.68697 


\begin{abstract}
This article seeks to connect the economic and political context of the second half of the twentieth century to the discussion of democracy and social participation in order to analyze institutional arrangements like the economic and social councils as a social dialogue alternative. The neoliberal policies implemented in the late twentieth and early twenty-first centuries have led democracy into a crisis of representation and legitimacy. One of the alternatives often aimed at solving or alleviating this crisis is to expand social participation through institutionalized forms of social dialogue. Based on the experience of the economic and social councils, this paper questions these entities as a path to overcome the crisis of democracy. The root of the problem seems to lie in neoliberal policies, which reduce state regulation and aggravate social inequality, allowing economically powerful groups to hold sway over political representatives in various ways, thus contaminating spaces for representative democracy and alternative dialogue, as seems to be the case with economic and social councils.
\end{abstract}

Keywords: Neoliberalism, democracy, inequality, social participation, economic and social councils.

\title{
Resumen
}

Este artículo busca vincular el contexto económico y político de la segunda mitad del siglo XX a la discusión sobre democracia y participación social para analizar los arreglos institucionales, como los consejos económicos y sociales, como una alternativa de ampliación del diálogo social. Las políticas neoliberales implementadas a fines del siglo XX y principios del siglo XXI han Ilevado a la democracia representativa a una crisis de legitimidad. Una de las alternativas frecuentemente presentada para resolver o amenizar dicha crisis es ampliar la participación social a través de un dialogo social institucionalizado. Con base en la experiencia de los consejos económicos y sociales, este artículo cuestiona esta salida para superar la crisis de la democracia representativa. La raíz del problema parece estar en las políticas neoliberales, que reducen la regulacion estatal y profundizan la desigualdad social, liberando el poder económico para capturar representantes políticos de diversas maneras y, así, contaminar espacios democráticos representativos y diálogos alternativos, como parece ser el caso de los consejos económicos y sociales.

Palabras clave: Neoliberalismo, democracia, desigualdad, participación social, Consejos económicos y sociales.

\section{INTRODUÇÃO}

A crise financeira de 1929 e a depressão que a seguiu nos anos 1930 colocaram em xeque a visão econômica predominante à época, segundo a qual o livre mercado seria capaz de garantir o equilíbrio macroeconômico com pleno emprego dos fatores de produção, trabalho inclusive. Os índices de desemprego elevados e resistentes nos países mais dinâmicos do sistema capitalista e a possibilidade crescente de convulsões sociais abriram espaço para uma maior intervenção do Estado na economia em meio à fermentação da teoria keynesiana.

De fato, ao longo da década de 1930, o Estado assumiu, em diversos países, em maior ou menor grau, o compromisso de implementar políticas para a manutenção do pleno emprego tendo em vista, entre outros objetivos, harmonizar minimamente os interesses de distintas classes sociais.

O sucesso da intervenção estatal para superar a depressão econômica colocou a teoria geral de Keynes e suas derivações no centro do pensamento econômico e marginalizou a tradição liberal que, embora combatida, se impôs ao longo do século XIX. Entretanto, nos anos 1940, os críticos de Keynes e da intervenção estatal na economia preparavam um contra-ataque tanto no plano da teoria econômica, como nos planos filosófico e político. O caminho da servidão, de Friedrich Hayek, publicado em 1944, lançou a crítica à intervenção estatal como ofensa à liberdade individual e à ideia de promover, via Estado, 
uma sociedade menos desigual (Anderson, 2008).

Essa crítica basilar não encontrou eco no pós-segunda guerra. A predominância da teoria keynesiana na academia e o próprio crescimento econômico apresentado pelos países mais desenvolvidos no período mantiveram o neoliberalismo no gelo de Mont Pèlerin. Entretanto, o neoliberalismo colocou em marcha seu contra-ataque na crise dos anos 1970 ao ganhar espaço junto a acadêmicos e formuladores de política econômica.

A crise econômica desse período, expressa no fenômeno da estagflação, ensejou uma reação do eleitorado, tanto nos Estados Unidos, quanto na Europa, à intervenção estatal e pôs de manifesto uma insatisfação social que acabou por eleger governos conservadores que colocariam em prática, sob a forma de política econômica, o ideário neoliberal. O desmantelamento da União Soviética no final dos anos 1980 e o soi-disant consenso de Washington no início dos anos 1990 marcaram o predomínio, no campo econômico, de um neoliberalismo aparentemente sem rivais e, no campo político, da democracia representativa como regime ideal (Fukuyama, 2006 [1992]).

E, de fato, entre 1970 e 1980, o neoliberalismo parecia ser a escolha democrática da vez. Paradoxalmente, a insatisfação da sociedade foi canalizada para a intervenção estatal que outrora buscou defendê-la das forças do mercado. Se no pós-guerra o Estado construiu as bases de uma proteção social, nesse período passou a ser visto como responsável pela combinação politicamente fatal de estagnação econômica e inflação. A crise do chamado Estado de bem-estar social foi capturada politicamente pelas forças conservadoras e abriu espaço para a eleição do neoliberalismo em diversos países. O discurso da crise de governabilidade apresentava um Estado inchado e incapaz de atender às novas demandas sociais. A receita para resgatar a governabilidade deveria conter três ingredientes fundamentais: privatização, mercantilização e liberalização (Santos, 2005b).

Por esse motivo, governos recém-eleitos nesse período fizeram reformas previdenciárias, trabalhistas, tributárias, comerciais, bancárias etc. Essas reformas, todavia, trouxeram invariavelmente baixo crescimento econômico e aumento do desemprego, o que afetou a própria credibilidade das instituições democráticas, pois a defesa dos direitos sociais conquistados nos anos posteriores à segunda guerra perdeu força vis-à-vis a influência do mercado sobre as decisões políticas e marcou o esvaziamento da representatividade popular e a ascensão do establishment político e econômico, especialmente nas décadas de 1970 e 1980.

Theuer e Bresser-Pereira (2012) mostraram que a política neoliberal resultou em baixo crescimento econômico e aumento do desemprego. Przeworski (1993) também argumenta que essa política, em vez de trazer estabilidade e crescimento econômico, causou recessão e grande perda democrática, já que o poder de decisão estaria com agentes externos e não com representantes eleitos. A perda da credibilidade da democracia nesse contexto é apresentada por Fiori (1997) e Tarragó, Brugué e Cardoso Jr. (2015), sob a perspectiva do pensamento único. A alternância de poder, nesse caso, estaria comprometida, uma vez que todos 
os partidos deveriam seguir a mesma política majoritariamente subordinada ao poder econômico.

Se entendermos a democracia fundamentalmente como espaço do dissenso, o neoliberalismo a colocou em xeque ao tentar criar um consenso em torno de si mesmo. Talvez resida aí uma das contradições mais importantes entre o neoliberalismo e a democracia. A perda de credibilidade das instituições democráticas desde aquela época passa pela tentativa de impor um pensamento único às alternativas políticas e, enfim, à sociedade. Qualquer alternativa à receita neoliberal, sobretudo no campo econômico, era logo desqualificada ou apresentada como o caminho para o caos social. A construção de um Estado mínimo, com orçamento equilibrado e políticas econômicas previsíveis, seria condição sine qua non para disparar o ímpeto empreendedor dos indivíduos e o investimento privado. Qualquer resultado diferente de crescimento econômico e geração de empregos, no entanto, seria debitado na conta do Estado e indicaria a necessidade de mais reformas para reduzi-lo.

O discurso e a prática foram adotados por variados espectros do campo político, seja por opção, seja por pressão, dos chamados mercados e das instituições multilaterais que também cumpriam seu papel na difusão das políticas neoliberais. A partir daí, partidos socialistas e conservadores, agremiações consideradas de esquerda e de direita, passaram a seguir praticamente a mesma receita de reformas sob um intenso discurso de terror econômico caso optassem por um caminho diferente. Assim, o neoliberalismo limitou a alternância de poder e relativizou a soberania política dos países que o ado- taram uma vez que substituiu, em boa medida, a interferência democrática nas decisões políticas e econômicas pela força da influência do mercado, por meio do dinheiro para financiar campanhas eleitorais, e do lobby de grandes corporações. Nos Estados Unidos, a aliança entre o partido democrata e o setor financeiro na construção da política econômica de corte neoliberal ainda na década de 1970 é um exemplo desse processo, como mostrou Matt Stoller (2016) em artigo na revista The Atlantic.

A gestão pública também foi influenciada pelo neoliberalismo, e as instituições anglo-saxãs foram consideradas modelos e reproduzidas em governos de diversos países, conjuntura denominada por Evans (2003) de "monocultura institucional". Decisões políticas ganharam verniz técnico, o discurso da eficiência minou debates dentro e fora do governo, e cálculos de custo-benefício indicaram a viabilidade econômica da oferta dos serviços públicos, indicando invariavelmente sua diminuição e transferência para o setor privado.

Nessas condições, de ausência de debate e imposição de um consenso, a democracia restringiu-se praticamente ao direito de voto, formalidade despida de sua possibilidade transformadora da realidade social, com alternância de poder e liberdade de escolha das políticas públicas pelos governos eleitos e, por conseguinte, pela população. Prevaleceu a ideia de que as necessidades sociais seriam mais bem atendidas por meio do mercado, relegando a segundo plano a noção de direitos sociais que havia guiado a montagem do Estado de bem-estar no período posterior à segunda guerra. A imposição do mercado sobre a política e os direitos 
acarretou perda de confiança na democracia (Estanque, 2006) e descrença na política (Tarragó et al., 2015). Isso, certamente, ajuda a explicar a alienação da participação social e a formação de um agrupamento não desprezível de pessoas com forte sentimento antiestablishment, chamadas por Streeck (2017) de "recalcadas" (repressed).

De fato, as políticas neoliberais e suas consequências econômicas, como o aumento da desigualdade social, desgastaram a democracia representativa e a própria imagem dos políticos e da política. Apesar do voto, o establishment se distanciou da população e os representantes dos representados, pois a estabilidade política dependeria mais da proximidade com a elite econômica e a implementação da política neoliberal. A ampliação do diálogo social surgiu nesse contexto como alternativa para tentar resgatar a crença na democracia e em seu papel transformador. Seria uma tentativa de remontar a resistência ao mercado para tornar a democracia representativa mais participativa e efetiva, em contraposição ao poder do capital e, enfim, estancar a ruína da representação. Andaimes institucionais, como os conselhos econômicos e sociais, foram erguidos para tentar evitar maior degradação da democracia representativa no contexto neoliberal. Entretanto, o que se pretende discutir neste estudo é que esses novos espaços de diálogo social institucionalizado aparentemente não são suficientes para enfrentar o problema da participação, pois sua raiz talvez não esteja no modelo de democracia representativa, mas sim na desigualdade derivada das políticas neoliberais.

Para organizar minimamente a discussão, este artigo está estruturado em três partes.
A primeira, mais teórica, discute brevemente alguns modelos de democracia, tendo como objetivo chegar ao conceito de democracia de equilíbrio de Macpherson (1979). A segunda, mais histórica, trata da ascensão do neoliberalismo e da predominância da democracia meramente formal. A terceira parte trata da participação social e do diálogo social institucionalizado como alternativas para superar a crise da democracia representativa. Finalmente, vale ressaltar que este estudo é resultado parcial de uma profunda pesquisa documental sobre os conseIhos econômicos e sociais de Espanha, Portugal e Brasil. Embora não seja apresentada aqui, essa pesquisa serviu como base para a reflexão que segue.

\section{MODELOS DE DEMOCRACIA E DEMO- CRACIA DE EQUILÍBRIO}

A implementação das políticas neoliberais e, sobretudo, a desregulamentação dos mercados financeiros na década de 1990 e início da de 2000 aprofundaram a concentração de renda nos países mais desenvolvidos e, com ela, a influência do mercado sobre os representantes eleitos no processo decisório de governos (Reich, 2013; Streeck, 2014). O diálogo social institucionalizado, por outro lado, apresentou-se como contrapeso a tal influência, tendo como estratégia ampliar a participação dos representados. A discussão sobre democracia representativa e participação não é nova e remete, inicialmente, ao estudo dos modelos de democracia. O propósito, todavia, não é discorrer longamente sobre eles ou sobre a questão da representação e participação direta, assuntos extensos e complexos, mas apenas ressaltar a relação entre economia e política, entre mercado e participação, funda- 
mentada em uma interpretação específica dos modelos de democracia (Macpherson, 1979).

Como apontado por Sipioni e Silva (2013), já no início século XX, discutia-se a preponderância da representatividade sobre a participação nos modelos democráticos, sendo que, na primeira metade desse século, estudiosos como Weber e Kelsen supervalorizavam o papel dos mecanismos de representação, enquanto, na segunda metade, autores como Habermas já levantavam a necessidade de ampliar os mecanismos de participação.

Entretanto, para chegar à discussão proposta neste artigo, é preciso combinar os aspectos econômico e político na análise da democracia. Macpherson (1979) faz esse movimento com o conceito de democracia liberal ao juntar representação política e mercado livre. A partir daí, apresenta três modelos teóricos de democracia, dos quais o mais interessante para este estudo é o denominado democracia de equilíbrio.

O modelo inicial, denominado por ele de democracia protetiva, foi apresentado pelos utilitaristas Jeremy Bentham e James Mill. Nele, a defesa da propriedade privada era primordial e entendia-se necessário o voto secreto, periódico e universal para garantir a felicidade para o maior número de pessoas, preceito da filosofia utilitarista. A raiz da democracia nesse modelo estava, portanto, na segurança da propriedade privada e na garantia do voto. Não havia preocupação com a igualdade social ou com a transformação da sociedade, pois a defesa da democracia se baseava na conservação de interesses individuais por meio do voto $\mathrm{e}$ não pela transformação social.

O segundo modelo, chamado de democracia desenvolvimentista, foi desenhado por John Stuart Mill e, segundo MacPherson (1979), prevaleceu até meados do século XX. Em vez de centrar-se na defesa da propriedade privada, como o anterior, esse modelo se preocupou com a desigualdade social por considerá-la um obstáculo ao pleno exercício da democracia. Isso ocorre porque a visão de ser humano implícita no modelo o entendia não como mero consumidor ou proprietário, mas como um desenvolvedor e desfrutador de suas potencialidades plenas. Por esse motivo, a democracia não se resumiria ao sufrágio, embora isso fosse um de seus aspectos essenciais, e passaria a ter um valor moral na busca pelo desenvolvimento da humanidade.

O terceiro modelo, denominado democracia de equilíbrio, prevalecia no momento em que Macpherson (1979) elaborou seu livro e se fortaleceu com a ascensão do neoliberalismo. Esse modelo, intimamente ligado aos mecanismos de mercado e posto em marcha depois da segunda guerra, corresponde aproximadamente ao que Streeck chamou de "capitalismo democrático". A democracia é inserida na lógica do mercado, os cidadãos são vistos como consumidores e os políticos como empreendedores em busca de voto e, consequentemente, da permanência no poder. Ela se torna, dessa maneira, apenas um mecanismo de escolha de governos, garantindo aparentemente o exercício da soberania popular, o que indica o equilíbrio entre representantes eleitos e eleitores representados.

Contudo, o efeito da desigualdade social 
entre representantes e representados e na soberania popular não é considerado. Além disso, como o aspecto fundamental desse modelo é o sufrágio universal, tratando-se de uma visão meramente procedimental da democracia, é comum que a sociedade só se mobilize nas eleições, restando uma conveniente apatia depois de divulgados os resultados das urnas. Embora observado desde o pós-guerra, esse modelo acabou se fortalecendo, no contexto neoliberal, com o reforço da visão individualista - uma cabeça, um voto -, sobrevalorizando o sistema representativo em contraponto à participação, o que compromete o papel da mobilização (Estanque, 2006). O mecanismo democrático corresponderia apenas à competição por votos de políticos que obteriam o direito de governar até a próxima eleição, sendo que o resultado não representaria necessariamente a decisão da população sobre as políticas a serem implementadas, apenas definiria o governante. Não obstante, a eleição periódica serviria como uma espécie de proteção para a população contra a tirania do eleito.

Procurava-se, assim, por meio da eleição periódica de representantes, amenizar as tensões entre economia capitalista e democracia representativa inerentes ao que Streeck (2011, p. 7) caracterizou como capitalismo democrático:

... uma economia política guiada por dois princípios ou regimes de alocação de recursos conflitantes: um opera de acordo com a produtividade marginal, ou o que é revelado como mérito pelo "livre jogo das forças de mercado," e outro baseado na necessidade ou direito social, definidos pelas escolhas coletivas da política democrática [tradução dos autores].
Nos 30 anos posteriores à segunda guerra, o controle político subordinou o poder econômico num quadro em que a intervenção do Estado resultou em maior estabilidade econômica e menor desigualdade social nos países desenvolvidos (Piketty, 2014; Reich, 2013), o que não significa a ausência de crises (Streeck, 2011). A atuação de sindicatos de trabalhadores, o objetivo social e governamental do pleno emprego e o próprio controle estatal sobre determinados setores da economia garantiram, de certa maneira, o equilíbrio instável sobre o qual repousava a democracia no período, isto é, o arranjo político, numa conjuntura de crescimento econômico, era suficientemente flexível para acomodar os interesses de direita e esquerda, de pobres e ricos, das demandas do mercado e dos direitos sociais. No entanto, essa tensão teria sido apenas amenizada num contexto favorável, mas não eliminada, uma vez que é inerente ao capitalismo democrático ou à democracia de equilíbrio.

A democracia de equilíbrio, ao colocar como pressuposto básico o sufrágio universal, despe-se de qualquer valor moral quanto à mudança desejada pelo conjunto da sociedade. Entretanto, é possível imaginar que a simples outorga do direito ao voto a todo cidadão acarretaria a ascensão da classe trabalhadora ao poder, já que o número de operários superaria com folga o de capitalistas. De fato, alguns socialistas pensavam que 0 sufrágio universal fosse a maior ameaça ao sistema capitalista (Przeworski, 1988).

Na realidade, a maioria operária não se refletiu em votos para os socialistas como se esperava. Ao contrário, para serem eleitos e conquistarem certo poder político, parte do 
espectro político socialista fez concessões aos seus ideais iniciais. Por exemplo: o endosso à propriedade privada e a proteção ao lucro, que acabaram por fortalecer o próprio capitalismo (Przeworski, 1988). Contudo, é preciso considerar que, de certo modo, o arranjo da democracia de equilíbrio ou do capitalismo democrático no pós-guerra foi bem-sucedido ao matizar o medo que a direita tinha dos pobres e a desconfiança que a esquerda nutria dos ricos (Streeck, 2011). A pauta que compatibilizava interesses era a defesa de um capitalismo com políticas sociais implementadas pelo Estado.

Para MacPherson (1979), não seria surpresa verificar a migração de partidos socialistas para o campo social-democrata, uma vez que, para ele, em qualquer sistema partidário, era importante que o partido adotasse uma posição mediana, de equilíbrio entre os conflitos de classe, caso pretendesse adquirir votos da maioria necessários para vencer as eleições. Posições radicais não tinham perspectiva de vitória em votações majoritárias. Outro ponto a trazer a necessidade de posições medianas decorre da relação estreita no capitalismo entre os desempenhos econômico e político. Era preciso proteger a propriedade privada e o lucro porque delas dependiam o crescimento da economia e, consequentemente, a distribuição da renda na sociedade. Vem daí um dos vínculos mais importantes entre democracia e capital e uma das barreiras mais fortes para a adoção de medidas que contrariem os interesses deste último. $\mathrm{Na}$ mesma linha, Offe e Ronge (1975, p. 140) afirmam que qualquer governo numa sociedade capitalista depende do capital. A natureza das forças políticas que sobem ao poder não afeta essa dependência, pois ele é estrutural: uma característica do sistema e não dos ocupantes do governo, vencedores das eleições. Por isso, no contexto capitalista e, sobretudo, neoliberal, "estar no poder não significa necessariamente ter muito poder" (Przeworski, 1988, p. 77).

\section{TRANSIÇÃO ENTRE MODELOS: RUMO À DEMOCRACIA NUM CONTEXTO NEOLI- BERAL}

O Estado de bem-estar social montado nos países desenvolvidos no pós-guerra se fragilizou com a crise econômica de meados da década de 1970, motivada, basicamente, pela queda da produtividade e do lucro. $\mathrm{Na}$ esteira dessa crise, os partidos social-democratas também se fragilizaram e perderam força política para os partidos conservadores, que difundiam o discurso da ineficiência do Estado criado pelos adversários e a necessidade urgente e evidente de sua diminuição (Przeworski, 1988).

No campo econômico, o modelo keynesiano de intervenção do Estado na economia foi posto em causa pelo discurso liberal. Tal discurso se aproveitou habilmente do contexto de crise econômica para relacioná-la às políticas sociais e de pleno emprego então implementadas. $\mathrm{O}$ argumento era de que a intervenção do Estado afastou o investimento privado, quer pelo efeito crowding out, quer pela regulamentação ou tributação da propriedade e do capital.

No campo político, a ideia a ser difundida era de que o tamanho excessivo do Estado provocava também uma crise de governabilidade gerada pelo excesso de demandas, que dificultavam o alcance de consensos para a boa gestão (Santos, 2005b). O discurso da 
falta de governabilidade pôde ser observado tanto em países desenvolvidos quanto em desenvolvimento. Nos primeiros, foram adotadas medidas para diminuir as demandas do Estado; nos últimos, a governabilidade foi frequentemente mantida por regimes autoritários (Fiori, 1997).

Evidentemente, a crise econômica da década de 1970 coincidia com as políticas públicas que demandavam maior intervenção estatal, mas daí não se segue que essa teria sido a causa daquela. De qualquer modo, o contexto possibilitou aos conservadores a adoção de um discurso, legitimado pelas urnas: a necessidade de libertar o acúmulo dos grilhões impostos anteriormente pela social democracia (Dupas, 1998). E, como mencionado, o discurso foi tão forte que produziu modificações inclusive nos partidos progressistas.

A partir daí estava aberto o caminho para a implantação de políticas neoliberais nos anos 1980. Se antes a democracia era fundamental para definir a alocação dos recursos por meio da intervenção estatal e sua política econômica, no contexto neoliberal, o que importava era a adoção da política econômica considerada saudável (sound policy). É secundária a preocupação se as medidas seriam adotadas por regimes políticos democráticos ou autoritários. Anderson (2008) ressalta a flexibilidade da ideologia neoliberal no que tange à defesa da democracia. Ela seria bem-vinda somente se não interferisse na liberdade dos agentes econômicos. Um dos exemplos mais ilustrativos dessa flexibilidade foi o Chile de Pinochet e dos Chicago boys, grupo de economistas chilenos de orientação liberal formados na Universidade de Chicago.
Os discursos reformistas que vendiam a solução da crise econômica e de governabilidade foram centrados, basicamente, em duas dimensões: uma econômico-financeira, ligada à necessidade de um ajuste fiscal, e outra institucional-administrativa, referente à imperiosa mudança do aparato estatal com o objetivo de enxugá-lo para aumentar sua eficiência. O problema desses discursos é que a dimensão sociopolítica do Estado foi relegada ao segundo plano (Paula, 2005), já que não se diagnosticava qualquer problema de legitimidade na crise (Santos, 2005b).

Apesar do discurso, o que se observou em governos conservadores que adotaram políticas neoliberais foi o aumento dos gastos do governo, principalmente com os subsídios e juros da dívida pública nacional (Dupas, 1998), o que colocou em xeque a tese de falta de governabilidade em razão do gasto excessivo do Estado. De qualquer forma, ao longo dos anos 1990, organismos multilaterais, como FMl e Banco Mundial, passaram a ver como instrumentos para a gestão econômica e a governabilidade questões programáticas e normativas sem qualquer análise política. A pauta consistia em reformas práticas para o ajuste fiscal e pró-mercado (Fiori, 1997). As medidas elencadas no consenso de Washington já referido e a penetração do gerencialismo no setor público são dois exemplos desse movimento.

Na economia, como já mencionado, o que as políticas neoliberais trouxeram ao defender ajustes fiscais severos e cortes dos gastos estatais foram programas de estabilidade que, em vez de produzir o crescimento econômico, causaram recessão. $\mathrm{Na}$ administração pública, o gerencialismo voltou- 
-se para a gestão interna negligenciando a necessidade de participação social (Tarragó et al., 2015). O fortalecimento do mercado e a adoção das receitas preestabelecidas fizeram com que governos eleitos não necessariamente governassem de acordo com as demandas dos eleitores, já que estavam sujeitos ao poder econômico. Sindicatos de trabalhadores e redes de proteção social foram enfraquecidos. Aos poucos, anunciou-se uma crise de legitimidade em que a política passou a ser vista mais como problema do que solução, uma vez que a sociedade via seu poder de influência se reduzir e sua participação se restringir, praticamente, nas votações periódicas (Tarragó et al., 2015).

Já se comentou que, no neoliberalismo, a democracia não é um valor em si, já que o essencial seria a liberdade econômica dos indivíduos (Anderson, 2008). Além disso, trata-se de uma democracia formal relativa à possibilidade de votar e ser votado, ou seja: democracia de equilíbrio conforme os modelos apresentados anteriormente. Esperava-se o progresso econômico e social como resultado da democracia formal e liberdade econômica, entretanto, o que se verificou até a crise econômica de 2008 foi o aumento da desigualdade de renda (Piketty, 2014) e a intromissão cada vez maior de grandes corporações no ambiente das decisões políticas. Com a crise dos Estados, os chamados mercados começaram a ditar, quase sem contrapeso, o que os governos presumivelmente soberanos e democráticos deveriam fazer (Streeck, 2011). O processo de financeirização da economia mundial (Chesnais, 1996), resultante em boa medida da política neoliberal de desregulamentação financeira, esvaziou a autonomia dos Estados na definição da política econômica
(Dupas, 1998), como pôde ser observado no caso grego de 2015.

Outro exemplo é a doutrina da austeridade fiscal (Islam, 2014) imposta a diversos governos independentemente da coloração partidária, apesar dos resultados negativos alcançados pelos que já a praticaram e da controvérsia teórica sobre sua efetividade para gerar crescimento econômico. As políticas de ajuste fiscal têm sido apresentadas à sociedade como urgentes, inevitáveis e inegociáveis, ou seja, não há espaço para o debate de alternativas. Isso significa, em outras palavras, um esvaziamento também da democracia, pois os poderes de decisão não estão mais com os eleitos, mas sim com os agentes externos (Przeworski, 1993). Esse conjunto de coisas tem levado a um clima social tenso, com protestos e paralisações nos países que as têm adotado, haja vista a inexistência de abertura para discussões a respeito de soluções alternativas. Para se contrapor a essas políticas, estavam abertos apenas os protestos e questionamentos judiciais, excluindo o plano político, ao qual era inegociável a aprovação das medidas de ajuste (Papadakis \& Ghellab, 2014).

Entre 2008 e 2009, houve um breve interregno com políticas intervencionistas e ampliação da participação social, vista como uma forma de mitigar os efeitos da crise. Contudo, as políticas neoliberais foram retomadas em 2010, sobretudo na Europa, mesmo diante da contestação social e de especialistas (Krugman, 2012; Stiglitz, 2010). Foi justamente após garantida a liquidez pela injeção de grandes valores no mercado pelo Estado, que o mercado e os agentes externos impuseram a razão do ajuste fiscal como forma de garantir o pagamento de seus emprésti- 
mos. Não havia alternativa e, com isso, o diálogo social encetado no pós-crise se exauriu, porque foi visto como grande empecilho para a continuidade ou retomada das reformas liberalizantes (OIT \& AICESIS, 2013). No momento em que políticas neoliberais foram retomadas, agravou-se a crise de governabilidade.

A análise histórica da relação entre neoliberalismo e democracia revela que o aprofundamento das políticas neoliberais, tendo a liberdade econômica individual como fundamento da sociedade, voltou a tensionar as relações contraditórias amenizadas no pós-guerra, distanciou o controle político do poder econômico e reforçou o caráter meramente formal da democracia.

\section{SUPERAÇÃO DO MODELO DE EQUILÍ- BRIO: PARTICIPAÇÃO SOCIAL E O CASO DOS CONSELHOS ECONÔMICOS E SO- CIAIS}

A ampliação da participação popular seria uma alternativa, apontada por MacPherson (1979), para romper com esse modelo de democracia liberal prevalente. O modelo chamado por ele de democracia participativa sugere a criação de uma democracia inclusiva, não restrita ao sistema político representativo e, enfim, ciosa de seu aspecto moral.

Na segunda metade do século $X X$, vários autores começaram a entender que a ruptura do modelo de democracia de equilíbrio seria possível apenas por meio da ampliação da participação social, como é o caso já referido de Habermas. Surgiram então correntes teóricas distintas, mas favoráveis à ampliação da participação social como forma de fortalecer a democracia. Lüchmann (2014) sistematizou as três principais correntes existentes: a primeira defende que o associativismo pode gerar um capital social, em contraponto ao individualismo inerente ao capital financeiro, ao trazer ganhos à sociedade, fazendo-a mais cooperativa, solidária e tolerante; a segunda trabalha a questão dos movimentos sociais que podem ter origem de uma ação coletiva para contestar e mudar uma realidade política ou cultural; a terceira corrente traz a possibilidade de se reforçar o papel da sociedade civil, como núcleo de discussão de problemas políticos e econômicos que surge com base uma ação comunicativa para questionar a ordem vigente em que o Estado e o mercado se sobrepõem ao indivíduo.

Em qualquer das correntes resumidas antes, a participação social passa a ter um papel fundamental para se contrapor aos efeitos do neoliberalismo sobre os regimes democráticos. Ainda segundo Lüchmann (2014), a participação social pode gerar três efeitos aptos a fortalecerem o progresso democrático. O primeiro é individual, ligado à maior conscientização do cidadão de seus direitos e deveres, bem como à necessidade de maior participação política, provendo-o de capacidade para julgamentos autônomos. O segundo é público, ligado ao aumento do vínculo social e à maior sensibilidade aos problemas sociais. O terceiro efeito é político-institucional, ligado à ampliação e à qualificação da representação política, ao exigir maior prestação de contas dos representantes, uma vez que impõe maior poder de resistência em face da distribuição desigual de poder.

Por meio da participação social, novas so- 
luções poderiam surgir e ficar evidente que haveria espaço para o debate de alternativas em oposição à retórica do pensamento único que desencadeou um processo de crise moral da democracia representativa com a perda da distinção dos partidos (Fiori, 1997). Nessa questão, surge um interessante paradoxo, pois foi justamente no momento em que se consolidou a existência concomitantemente de capitalismo e democracia, com a garantia do sufrágio universal, que se perdeu o encanto com a democracia e afloraram as crises de legitimidade.

Esse desencanto não seria revertido apenas com a ampliação da participação social. De acordo com Avritzer e Santos (2002), o modelo de democracia hegemônico, que se confunde com a democracia de equilíbrio apresentada por Macpherson (1979), apresentou duas grandes patologias: a apatia social e a percepção de que os eleitos não representam os eleitores. No entanto, ambas seriam funcionais na democracia de equilíbrio, uma vez que a primeira desmobiliza a sociedade no debate de questões importantes e o transfere para as esferas do executivo e legislativo, e a segunda marca a separação dos interesses do eleito e do eleitor, apesar do voto. Para Macpherson (1979), esses dois aspectos, presentes no modelo democrático predominante, são estruturais e devem permanecer enquanto não for trabalhada a questão da desigualdade social, sob pena de ruptura do modelo. Os "recalcados" mencionados anteriormente, críticos do establishment, expressão da crise da democracia, seriam fruto dessa desigualdade legitimada pelo Estado, o que teria levado ao distanciamento entre os interesses das elites e do povo.
A desigualdade social afeta o aspecto democrático e interfere diretamente na igualdade política, a qual se restringiu no regime neoliberal basicamente ao sufrágio universal. $O$ aumento da desigualdade interfere na igualdade de direitos civis e políticos, pois os recursos econômicos podem ser convertidos em direitos políticos. Os direitos políticos, para serem exercidos, não se esgotam pelo voto. É necessária, ainda, a possibilidade de participação e interferência no processo democrático e, nisso, a disponibilidade de recursos econômicos importa para a efetivação dos direitos políticos (Kerstenetzky, 2002), principalmente pelo aumento do valor necessário para o financiamento das campanhas.

Ademais, a capacidade associativa entre os cidadãos, com o objetivo de influir na esfera pública, sofre interferência dessa desigualdade, porque há correntes teóricas. Como expõem Silva e Zanata Jr. (2008), a desigualdade extrema impede e desestimula 0 engajamento das classes subalternas e das classes do alto da pirâmide social, que apresentam outros instrumentos de acordo. A coparticipação entre ambos os extremos da pirâmide social é afetada, já que a distância social cria fortes barreiras de relação entre indivíduos e grupos, ou seja, quanto mais afastadas socialmente as classes, menor a probabilidade de construir relações e interesses comuns.

No Brasil, no início do funcionamento do Conselho de Desenvolvimento Econômico e Social, verificou-se a dificuldade de coparticipação dos extremos da pirâmide: empresários e movimentos sociais. A classe empresarial entendeu que a pressão por políticas públicas que lhe fossem favoráveis poderia 
ser exercida por outros meios, enquanto os movimentos sociais, raramente escutados nas definições de grandes políticas para o país, adotaram posições radicais que travaram a possibilidade do diálogo social (Fleury, 2006).

Estanque (2006) observa que o aumento da desigualdade verificado no período de implementação das políticas neoliberais afastou o cidadão da participação nos rumos políticos do Estado, gerou uma crise no sistema representativo e levou o eleitor a vincular a atividade política a práticas suspeitas. Toda essa realidade de predomínio ideológico neoliberal acabou desinteressando o cidadão de interferir na mudança dos rumos por meio de um sistema político desacreditado. Como afirmam Tarragó et al. (2015, p. 16): "A crise de legitimidade é tão profunda que a política deixou de ser a solução para tornar-se parte do problema".

Na mesma linha, Macpherson (1979) e Kerstenetzky (2003) afirmam que a desigualdade pode trazer uma apatia das classes sociais mais baixas, principalmente pela falta de poder de influência no processo decisório, já que não dispõe de recursos aptos a efetuar o financiamento de campanhas, gerando, com isso, uma ideia de conformismo ao entender não ser possível mudar a estrutura econômica vigente.

Por outro lado, os teóricos defensores do modelo de democracia de equilíbrio entendem que esse sistema democrático de elite permite trazer um equilíbrio ótimo entre o interesse da elite econômica e a soberania popular nos moldes do período posterior à segunda guerra. No entanto, é preciso considerar que, nessa época, o equilíbrio democrático assentava-se precariamente na redução da desigualdade social e, consequentemente, na possibilidade de participação política decorrente da política econômica de intervenção estatal ou do controle político sobre o poder de mercado. A tensão social voltou a subir com as políticas liberalizantes e a concentração de renda delas decorrente. Se o poder de mercado em fazer valer seus interesses se ampliou nesse período, a apatia social prevaleceu na manutenção e busca de direitos.

Como um dos principais instrumentos associativos de classes subalternas, os sindicatos poderiam exercer um papel de contrapeso ao poder econômico das grandes corporações, mesmo numa democracia de equilíbrio em contexto neoliberal. No entanto, o desemprego, a desregulamentação dos mercados de trabalho e as crises acabaram diminuindo seu poder de influência nas decisões econômicas. Com isso, os movimentos sindicais entraram numa grave crise no mundo no final da década de 1980 (Santos, 2005a).

As reformas neoliberais no mundo do trabaIho trouxeram uma descrença no processo de associação sindical, com perda de seu poder e com contestação de sua legitimidade. A flexibilização das relações trabalhistas e o processo de descentralização da produção, ambos ligados à lógica econômica neoliberal, contribuíram para que isso ocorresse já que apresentou maior divisão dos trabaIhadores.

A divisão entre os trabalhadores é traduzida por Santos (2005a) em duas formas de sindicalismo: de contestação e de participação. Enquanto o primeiro centra suas forças 
na contestação do capital, rejeitando tudo a ele atrelado, o outro se propõe a participar, inclusive com coligações a partidos políticos, com submissão maior ao capital. Essa dicotomia acabou acarretando uma divisão e suspeição entre os movimentos sindicais. Na realidade, como aponta, Santos (2005a), ao contrário do que se pensava do movimento operário do século XIX, foram os capitalistas de todo o mundo que se uniram nesse processo de globalização e não os operários. O movimento operário ficou mais preocupado com questões internas, relativas ao valor do salário ou ao desemprego, enquanto os empresários e governos centraram suas preocupações nas políticas econômicas internacionais, o que acabou reforçando a desigualdade política existente. A institucionalização de um diálogo social com a participação direta da sociedade civil tem sido pensada e praticada em diversos países como alternativa para reduzir a desigualdade política entre trabalho e capital. A Organização Internacional do Trabalho (OIT, 2007) apresenta recomendações aos integrantes quanto ao aspecto de abertura ao diálogo e reforça a importância de fortalecimento das instituições representativas.

Avritzer e Santos (2002) apresentam a importância da participação social para se contrapor à concepção hegemônica de democracia. Com efeito, eles afirmam que as sociedades capitalistas consolidaram essa posição hegemônica para que fosse controlada e estabilizada a tensão gerada entre democracia e capitalismo, evitando uma sobrecarga de demandas democráticas. A participação social seria um instrumento, portanto, contra-hegemônico, já que permitiria a inovação democrática com a inclusão de temas ignorados pelo sistema político e geraria a sensação de pertencimento.

Na mesma linha, Estanque (2006) sustenta que a participação social com a criação de políticas favoráveis a esse aspecto pode minorar bastante os efeitos da desigualdade política e econômica verificada pela democracia liberal que se viu elitista, mas, para isso, entende ele que é preciso promover uma mudança cívica, empoderando o sujeito social com um papel ativo em contraponto ao individualismo neoliberal.

Esse ponto do sujeito social também é lembrado por Macpherson (1979), para quem o aumento da participação somente será possível quando houver uma mudança de visão do ser humano consumidor, trazendo-se novamente um valor moral à sociedade de busca do desenvolvimento da humanidade. Apesar do contexto neoliberal, o sujeito social deve deixar de ser apenas o trabalhador atomizado do início do século XIX e passar a ser entendido como os movimentos sociais organizados institucionalmente, com o propósito de serem capazes de fazer frente ao grande capital que está plenamente empoderado nesta sociedade (Houtart, 2007).

Da mesma forma, Santos (2005a) expõe a necessidade de revisão do modelo sindicalista e defende que seja ampliada sua visão operária para uma mais cidadã, introduzindo o princípio da solidariedade em seus ditames. Sua preocupação deve ultrapassar a mera relação de produção, ou seja, a defesa apenas dos empregados por melhores salários e condições de trabalho. Os sindicatos devem começar a se preocupar com toda forma de exclusão social e trazer para seu seio interesses também dos desempregados, idosos, jovens etc. Em suma, ainda que 
num contexto neoliberal e de desigualdade social, a ampliação do processo da participação social seria o necessário contraponto à influência do capital sobre a política.

Essa perspectiva chegou a ser vivenciada no Brasil com o funcionamento do Conselho de Desenvolvimento Econômico e Social, o qual, apesar do problema inicial apontado, estabeleceu um diálogo entre todos os agentes partícipes do diálogo. As opções não ficaram restritas aos interesses corporativos, mas vislumbraram soluções melhores para o país.

Contudo, Kerstenetzky (2003) questiona a defesa irrestrita de que a ampliação do processo de participação social pode neutralizar a desigualdade política e acarretar um progresso democrático. Essa crítica decorre da análise de que a desigualdade política é consequência da desigualdade social, como também concorda MacPherson (1979). Sem alterar a desigualdade econômica, a simples participação não tem o efeito de diminuir a desigualdade política. Nesse sentido, à medida que o neoliberalismo tende a reforçar a desigualdade social, torna-se difícil considerar a participação social como alternativa viável.

Com efeito, nesse mesmo sentido, Silva e Zanata Jr. (2008) afirmam que o associativismo tende a replicar a diferença social existente, contrapondo-se à visão mais favorável da sociedade civil. Para eles, o processo de participação social é marcado por uma segmentação fundamentados em recortes socioeconômicos, replicando-se as desigualdades constitutivas da sociedade. O problema trazido por Sipioni e Silva (2013) é que, quando o processo de participação é institucionalizado, como visto em conselhos econômicos e sociais, ao ser representativo, ele replica as mesmas questões relativas à representação política, ou seja, a participação não é efetivamente aberta à sociedade civil, mas feita por representantes com pouca necessidade de prestação de contas e com preponderância para aqueles com maior poder econômico e cultural, sendo que a indicação do representante é feita pelo próprio governo ou entidade.

O Conselho de Desenvolvimento Econômico e Social brasileiro é um exemplo disso, ao trazer preponderantemente, em sua composição inicial, a classe empresarial com seus componentes majoritários do estado com maior poder econômico no país: São Paulo (Pinto, 2004).

Assim, a despeito da possibilidade de o processo de participação social trazer efeitos democráticos, o que se tem visto, em sua institucionalização, é a réplica dos problemas da democracia representativa e a preponderância das desigualdades sociais.

Avritzer e Santos (2002) também levantam esse problema da participação social que se tem visto na concepção hegemônica de democracia liberal. Ela sofre dois tipos de pressão: ser combatida ou ser cooptada.

Essas pressões refletiram, na perspectiva de participação, no âmbito do Conselho de Desenvolvimento Econômico e Social. Com sua criação, os agentes envolvidos não acreditavam no novo espaço institucional, enxergando-o como um ambiente arriscado tendente a ser monopolizado pelo governo ou por agentes estratégicos, vinculados a determinados interesses, em detrimento do 
diálogo aberto e profícuo (Cardoso Jr, Santos \& Alencar, 2010).

Para Kerstenetzky (2003), uma sociedade civil densa, mais participativa, pode até diminuir os impactos da cooptação realizada, mas não quer dizer que isso trará equilíbrio na participação política. Assim, a desigualdade política somente poderia ser minorada por duas formas: reformas pontuais no processo eleitoral, citando como exemplo o financiamento público de campanha, e a regulação da mídia, ou políticas redistributivas, incidindo sobre a concentração de riquezas.

Outro problema é que as políticas neoliberais ensejaram frequentemente nos anos 1990 e 2000 crises econômicas em maior ou menor grau. Em momentos de crise, o diálogo social é limitado e o mercado e agentes externos têm maior liberdade para impor suas visões como algo inegociável e urgente (Papadakis \& Ghellab, 2014).

A experiência dos Conselhos Econômicos e Sociais da Espanha e de Portugal, após a crise de 2008, demonstra essa limitação, pois grandes decisões foram tomadas, sob forte pressão, sem abertura para discussão (OIT \& AICESIS, 2013).

Para exemplificar, convém citar dois casos marcantes. Em 2013, foi aprovada na Espanha a reforma previdenciária, alterando, entre outras coisas, a idade mínima para concessão da aposentaria e, apesar de existir um histórico de diálogo naquele país a respeito de temas previdenciários, sendo o Pacto de Toledo um marco nesse aspecto, ela passou sem possibilitar um processo de participação efetivo, em razão da urgência apresentada (Molina \& Miguélez, 2014). Em Portugal, a limitação foi ainda mais evidente, pois, ao assinar o memorando de entendimento com a Troika (Comissão Europeia, Fundo Monetário Internacional e Banco Central Europeu), em troca de empréstimos do Banco Central Europeu, foi necessário efetuar ajustes impostos por órgãos externos. $O$ foco acabou sendo o ajuste fiscal, a despeito dos desequilíbrios a serem gerados, sem abertura para a apresentação de outros pontos (Penada, 2014).

Com efeito, apesar da perda de legitimidade do sistema representativo, do próprio esvaziamento do poder político, exercido pelo grande capital e por agentes externos, da grande desigualdade social existente e das crises econômicas que minam o debate democrático, a ampliação do processo da participação e do diálogo social institucionalizado tem sido apresentada como possível solução para os limites da democracia representativa, como no caso dos conselhos econômicos e sociais criados em diversos países no período neoliberal.

\section{CONSIDERAÇÕES FINAIS}

A democracia liberal pode configurar um padrão específico de desenvolvimento econômico capitalista com perfil socialmente inclusivo e amenizar as tendências à desigualdade e à exclusão social como se deu com o Estado de bem-estar social montado na segunda metade do século XX. Entretanto, a mesma democracia liberal pode justamente reforçar o círculo da desigualdade e exclusão social. Por isso, acreditamos não ser possível compreender a democracia fora do quadro econômico geral. A ideologia neoliberal interrompeu a preocupação com a desigualdade 
e o próprio desenvolvimento social, defendidos pelo Estado de Bem-Estar Social, mormente nos países em desenvolvimento, e transferiu ao mercado e ao indivíduo atomizado a solução das mazelas da sociedade. $O$ resultado das políticas neoliberais para a democracia, sobretudo com o reforço da desigualdade social, foram as graves crises de representação e legitimidade verificadas no final do séc. $X X$ e início do séc. $X X I$, que comprometem sua própria sobrevivência. Diante da crise democrática, surgiu o debate sobre as alternativas à democracia liberal e representativa. A participação social apareceu invariavelmente como opção para solucionar a crise. Canais de diálogo institucionalizados, inclusivos e participativos, apareceram nesse contexto como meio de operacionalizar a participação social, como os Conselhos Econômicos e Sociais.

De fato, o diálogo social se mostra essencial para tentar encontrar pensamentos inovadores, para além de políticas neoliberais como os ajustes fiscais, possibilitar a concertação social e motivar a participação dos cidadãos nas decisões políticas. Mais do que isso, faz-se necessária a rediscussão do aspecto moral da democracia, sem se centrar apenas em procedimentos. Para que isso ocorra, é importante a redução da desigualdade política e a garantia de sistemas sociais, com a inclusão da sociedade civil no processo de escolha das políticas públicas.

Entretanto, no contexto neoliberal, mesmo o diálogo social institucionalizado talvez não seja suficiente para superar a democracia meramente formal, porque os espaços de diálogo tendem a ser cooptados, dada a ampliação da força do mercado sobre a po- lítica, e reproduzir as políticas neoliberais legitimadas apenas formalmente pelo voto. $\mathrm{O}$ neoliberalismo está na raiz do problema porque, ao reproduzir e aprofundar a desigualdade social e reduzir a regulação estatal, libera o poder econômico para capturar de diversas maneiras os representantes, interromper diálogos alternativos e contaminar os espaços democráticos representativos, além de torná-los instâncias meramente legitimadoras de seus interesses. A experiência dos conselhos econômicos e sociais parece sinalizar os limites do diálogo social institucionalizado.

\section{REFERÊNCIAS}

Anderson, P. (2008). Balanço do Neoliberalismo. In: Sader, Emir et al. Pós-neoliberalismo. As políticas sociais e o Estado democrático. São Paulo: Paz e Terra.

Avritzer, L., \& Santos, B. de S. (2002). Para ampliar o cânone democrático. In: Santos, Boaventura de Sousa (org.), Democratizar a democracia: Os caminhos da democracia participativa. Rio de Janeiro: Civilização Brasileira.

Cardoso Jr., J. C., Santos, J. C., \& Alencar, J. (2010). Diálogos para o Desenvolvimento: A experiência do Conselho de Desenvolvimento Econômico e Social sob o governo Lula. Brasília: IPEA.

Chesnais, F. (1996). A mundialização do capital. São Paulo: Xamã.

Dupas, G. (1998). A lógica econômica global e a revisão do Welfare State: A urgência de um novo pacto. Estudos Avançados, 12(33), 171/183. 
Estanque, E. (2006). A questão social e a democracia no início do século XXI. Revista Finisterra, (55-56-57), 77-99.

Evans, P. (2003). Além da "Monocultura Institucional": instituições, capacidades e o desenvolvimento deliberativo. Sociologias, (9), 20-63.

Fiori, J. L. (1997). Globalização e governabilidade democrática. Physis - Revista Saúde Coletiva, 7(1), 137/161.

Fleury, S. (2006). O Conselho de Desenvolvimento Econômico e Social do Governo Lula. In: Martins, Paulo Emílio Matos, \& Pieranti, Octavio Penna. Estado e Gestão Pública. Visões do Brasil contemporâneo. 2. ed. Rio de Janeiro: FGV.

Fukuyama, F. (2006). The End of History and the Last Man. Nova York: Free Press.

Houtart, F. (2007). Os movimentos sociais e a construção de um novo sujeito histórico. In: A teoria marxista hoje: Problemas e perspectivas. Buenos Aires: Consejo Latinoamericano de Ciencias Sociales (CLACSO).

Islam, I. (2014). The rise and decline of the fiscal austerity doctrine: Implications for the Euro area crisis. In: Papadakis, Konstantinos, Ghellab, Youcef. The governance of policy reforms in southern Europe and Ireland: Social dialogue actors and institutions in times of crisis. Genebra: OIT.

Kerstenetzky, C. L. (2002). Por que se importar com a desigualdade. Dados. Revista de Ciências Sociais, 45(4), 649/675.
Krugman, P. (2012). Um basta à depressão econômica. Rio de Janeiro: Elsevier.

Lüchmann, L. H. H. (2014). Abordagens teóricas sobre o associativismo e seus efeitos democráticos. Revista Brasileira de Ciências Sociais, 29(85), 159/178.

Macpherson, C. B. (1979). The life and times of liberal democracy. Oxford: Oxford University Press.

Molina, O., Miguélez, F. (2014). From negotiation to imposition: Social dialogue in times of austerity in Spain. In: Papadakis, Konstantinos, \& Ghellab, Youcef. The governance of policy reforms in southern Europe and Ireland: Social dialogue actors and institutions in times of crisis. Genebra: OIT.

Offe, C., \& Ronge, V. (1975). Theses on the Theory of State. New German Critique, (6), 137-147.

Organização Internacional do Trabalho (2007). Fortalecimiento de los mecanismos institucionales para el diálogo social. Lima: Oficina Regional para América Latina y el Caribe.

Organização Internacional do Trabalho, \& AlCESIS - Associação Internacional dos Conselhos Econômicos e Sociais e Instituições Similares (2013). The Role and Impact of Economic and Social Councils and Similar Institutions (ESC-Sis) in the Response to the Global, Financial, Economic and Jobs Crisis. Madri: Governance and Tripartism Department - Internacional Labour Organisation.

Papadakis, K., \& Ghellab, Y. (2014). Introduction: Policy reform in southern Europe and 
Ireland and the role of social dialogue. In: Papadakis, Konstantinos, \& Ghellab, Youcef. The governance of policy reforms in southern Europe and Ireland: Social dialogue actors and institutions in times of crisis. Genebra: OIT.

Paula, A. P. P. de (2005). Administração Pública Brasileira entre o gerencialismo e gestão social. RAE-Revista de Administração de Empresas, 45(1), 36-49.

Penada, J. A. da S. (2014). Social dialogue as a new method of governance in Portugal. In: Economic and Social Council of Spain. The Economic and Social Councils in Latin America and the European Union: Practical experiences of social dialogue. Madri: EUROsociAL Programme.

Piketty, T. (2014). O capital no século XXI. Rio de Janeiro: Intrínseca.

Pinto, C. R. J. (2004). A Sociedade Civil "Institucionalizada". Política e Sociedade, 3(5), 101-117.

Przeworski, A. (1993). A falácia neoliberal. Lua Nova, (28-29), 209/225.

Przeworski, A. (1998). A social-democracia como fenômeno histórico. Lua Nova, 4(3), 41-81.

Reich, R. (2013). Aftershock. The Next Economy and America's Future. Nova York: Random House.

Santos, B. de S. (2005a). Teses para a renovação do sindicalismo em Portugal, seguidas de um apelo. In: Estanque et. al. Mudanças no trabalho e ação sindical: Brasil e Portugal no contexto da transnacionalização. São Paulo: Cortez.

Santos, B. de S (2005b). A crítica da governação neoliberal: O Fórum Social Mundial como política e legalidade cosmopolita subalterna. Revista Crítica de Ciências Sociais, 72, 7-44.

Silva, M. K., \& Zanata Jr., R. (2008). Desigualdade e associativismo: Proximidade espacial e distância social na conformação da sociedade civil. Revista Brasileira de Estudos Urbanos e Regionais, 10(2), 115-131.

Sipioni, M. E., \& Silva, M. Z. (2013). Reflexões e Interpretações sobre a participação e a representação em conselhos gestores de políticas públicas. Revista de Sociologia Política, 21(46), 147-158.

Stiglitz, J. (2010). O mundo em queda livre. São Paulo: Cia das Letras.

Stoller, M. (2016). How democrats killed their populist soul. The Atlantic. Disponível em: Recuperado de www.theatlantic.com/ politics/archive/2016/10/how-democrats-killed-their-populist-soul/504710

Streeck, W. (2017). The return of the repressed. New Left Review, (104), mar-abr. Recuperado de https://newleftreview.org/

Streeck, W. (2014). How capitalism will end? New Left Review, (87), maio-jun. Recuperado de https://newleftreview.org/

Streeck, W. (2011). The crisis of democratic capitalism. New Left Review, (71), set-out. Recuperado de https://newleftreview.org/ 
Tarragó, D., Brugué, Q., \& Cardoso Jr., J, C. Theuer, Daniela, \& Bresser-Pereira, Luiz Car(2015). A administração pública deliberativa: los (2012). Um Estado novo-desenvolvimenInteligência coletiva e inovação institucional tista na América Latina? Economia e sociea serviço público. Texto para Discussão $n$. dade, 21 (número especial), 811-829. 2122, Rio de Janeiro, IPEA. 